\title{
Forecasting for the Russian Economy Using Small-Scale DSGE Models ${ }^{1}$
}

\author{
Dmitry Kreptsev, Bank of Russia \\ kreptsevda@cbr.ru \\ Sergei Seleznev, Bank of Russia \\ seleznevsm@cbr.ru
}

This study examines the ability of a small-scale DSGE model to forecast the dynamics of key macroeconomic variables for the Russian economy. The study uses two versions of a standard model of a small open economy, adding a stochastic oil price trend under various assumptions about exchange rate policy. Comparison with the same size BVAR model shows DSGE models to be superior as regards exchange rate, price and interest rate forecasting and slightly inferior with respect to GDP forecasting.

Keywords: nonstationary DSGE, $B V A R$, forecasting

JEL: C61, E37, E47
Citation: Kreptsev, D., Seleznev, S. (2018). Forecasting for the Russian Economy Using SmallScale DSGE Models. Russian Journal of Money and Finance, 77(2), pp. 51-67

doi: $10.31477 /$ rjmf.201802.51

\section{Introduction}

Over the past decade, $\mathrm{DSGE}^{2}$ models have come into common use in both the academic community and central banks, government agencies and international financial organizations. This model class can be used to handle a wide range of tasks ${ }^{3}$, such as simulation experiments aiming to identify a model economy's responses, forecasting, etc.

\footnotetext{
${ }^{1}$ The authors wish to thank B. Gafarov, N. Kulagin, P. Molyakov, A. Morozov, A. Polbin, A. Ponomarenko, A. Porshakov, A. Sinyakov, and the anonymous reviewers for their help in conducting this study and for their useful comments. All mistakes are the authors' own.

${ }^{2}$ Dynamic stochastic general equilibrium models.

${ }^{3}$ Still, this model class (as any others) has certain disadvantages. Critique which applies to most of DSGE models is, for instance, found in Korinek (2015). A number of problems which researchers encountered during the latest crisis are described in Linde et al. (2015).
} 
In practice, a very wide variety of DSGE model specifications is employed, each tailored to the task at hand. Both large- and small-scale models are used in various applications. Central banks, for instance, increasingly widely rely on medium- and large-scale models (Cristoffel et al., 2008; Christiano et al., 2010; Adolfson et al., 2013; Burgess et al., 2013), while in research, preference is more often given to small-and medium-scale models (see, for instance, Lubik and Matthes, 2014; Maliar and Maliar, 2015; Fernandez-Villaverde et al., 2015; Aruoba et al., 2016; Diebold et al., 2016). ${ }^{4}$

This study examines the ability of two related small-scale DSGE models (differing in exchange policy assumption) to forecast the main macroeconomic variables (inflation, GDP, an interest rate, and the exchange rate) under given oil prices $^{5}$, while the Bayesian vector autoregression (BVAR), which has shown to be a better forecasting model for other countries (see Domit et al., 2016; Iversen et al., 2016), is viewed as an alternative to DSGE models. Although there exist a number of DSGE models for the Russian economy (see, for instance, Polbin, $2014^{6}$ ), this study is, to the best of our knowledge, the first attempt to examine DSGE models' conditional forecasting potential using the Russian data. Since this issue is understudied as regards the Russian economy, we are focusing on smallscale models, while large-scale models will be the subject of future research. We view Malakhovskaya (2016) as the most similar study based on Russian data, but the variable set used by the author is not quite conventional for this model type. Also, the study relies on unconditional forecasts, whereas we are focusing on conditional ones. All this precludes comparison of our findings with the results of Malakhovskaya (2016). ${ }^{7}$

Further presentation of the study is structured as follows. Section 2 describes the models. Section 3 deals with model solution and estimation. Section 4 discusses the results, and the last section sums up our findings.

\section{Model description}

The model presented in this paper describes a small open economy with the following agent types: households, firms, the external sector and a central bank. For simplicity, we do not introduce capital and also assume that oil accounts for the entire exports, revenue from which agents receive as endowment income. The rest of the structure, presented in Figure 1 (Appendix A), is conventional.

\footnotetext{
${ }^{4}$ Many effects interesting from the perspective of research can be illustrated based on small-scale models, whereas central banks seek to obtain as detailed description of their respective economies as possible.

5 The Bank of Russia provides this type of forecasts on a regular basis.

${ }^{6}$ Most of the DSGE models for the Russian economy are constructed using HP-filtered time series. Problems which can arise under this estimation procedure are described in Gorodnichenko and Ng (2010). This, it should be added, often makes these models inadequate for forecasting purposes.

7 The author also detrends indicators outside of the model, which usually weakens the models' predictive power, particularly that of BVAR models. This may account for the higher RMSFE values obtained in this study.
} 


\section{Households}

Household $\mathrm{j}$ chooses the level of consumption $C_{t}(j)$ and savings, as well as the number of hours worked $L_{t}(j)$, maximizing discounted utility (with discount factor $\beta$ ) given by

$$
U_{t}(j)=E_{t} \sum_{i=0}^{\infty} \beta^{i}\left(\ln \left(C_{t+i}(j)-h C_{t+i-1}\right)-A_{L} \frac{\left(L_{t+i}(j)\right)^{1+\phi}}{1+\phi}\right)
$$

where $A_{L}$ denotes household preferences regarding the number of hours worked, and $\phi$ is the coefficient inverse to elasticity of labor supply, and $h$ is the coefficient of habit formation.

Households face the budget constraint defining the relationship of income, expenditure and borrowings. In the period $t, j$-th household owns domesticand foreign currency-denominated assets $B_{t-1}(j)$ and $B_{t-1}^{*}(j)$, receives wages $W_{t}$ for hours worked $L_{t}(j)$ and transfers from firms $\Pi_{t}(j)$. These funds are spent to buy consumer goods $C_{t}(j)$ at price $P_{t}^{c p i}$ and domestic and foreign currency assets, respectively $\left(R_{t}\right)^{-1} B_{t}(j)$ and $\left(R_{t}^{*} r p\left(b_{t}^{*}, p_{t}^{\text {oil }}, z_{t}^{R P}\right)\right)^{-1} \mathcal{E}_{t} B_{t}^{*}(j)$. The resulting budget constraint is given by

$$
\begin{aligned}
P_{t}^{c p i} C_{t}(j) & +\left(R_{t}\right)^{-1} B_{t}(j)+\left(R_{t}^{*} r p\left(b_{t}^{*}, p_{t}^{o i l}, z_{t}^{R P}\right)\right)^{-1} \varepsilon_{t} B_{t}^{*}(j)= \\
& =W_{t} L_{t}(j)+B_{t-1}(j)+\varepsilon_{t} B_{t-1}^{*}(j)+\Pi_{t}(j)
\end{aligned}
$$

where $R_{t}$ is the domestic interest rate, $R_{t}^{*}$ is the foreign interest rate, $r p\left(b_{t}{ }^{*}, p_{t}^{\text {oil }}, z_{t}{ }^{R P}\right)$ is a risk premium depending on the relative debt level (see below), the real oil price and the stochastic part of the risk premium, and, $\mathcal{E}_{t}$ is the nominal exchange rate.

The first order conditions are then written as

$$
\begin{gathered}
1=\beta R_{t} E_{t}\left(\frac{c_{t}-h C_{t-1}}{C_{t+1}-h C_{t}} \frac{P_{t}^{c p i}}{P_{t+1}^{c p i}}\right) \\
1=\beta R_{t}^{*} r p\left(b_{t}^{*}, p_{t}^{o i l}, z_{t}^{R P}\right) E_{t}\left(\frac{c_{t}-h C_{t-1}}{C_{t+1}-h C_{t}} \frac{P_{t}^{c p i}}{P_{t+1}^{c p i}} \frac{\varepsilon_{t+1}}{\varepsilon_{t}}\right) \\
\frac{w_{t}}{P_{t}^{c p i}\left(C_{t}-h * C_{t-1}\right)}=A_{L}\left(L_{t}\right)^{\phi}
\end{gathered}
$$

Equations (1)-(3) are standard and have a natural economic interpretation. Equation (1), normally referred to as Euler's equation, defines the relation between the current and future consumption levels and is, effectively, the consequence of identical marginal utilities of current consumption (and current savings) and consumption in a future period given funds saved. 
Combining equations (1) and (2) yields the interest rate parity equation

$$
R_{t}=R_{t}^{*} r p\left(b_{t}^{*}, p_{t}^{o i l}, z_{t}^{R P}\right) \frac{E_{t}\left(\frac{C_{t}-h C_{t-1}}{C_{t+1}-h C_{t}} \frac{P_{t}^{c p i}}{P_{t+1}^{c p i}} \frac{\varepsilon_{t+1}}{\varepsilon_{t}}\right)}{E_{t}\left(\frac{C_{t}-h C_{t-1}}{C_{t+1}-h C_{t}} \frac{P_{t}^{c p i}}{P_{t+1}^{c p i}}\right)}
$$

Equation (3) represents the labor supply curve.

\section{Firms}

There are three types of firms in the model: domestic firms, importer firms, and aggregating firms which combine imported and domestic goods into final consumption goods.

\section{Domestic firms}

Employing wage labor $L_{t}(k)$, the $k$-th domestic firm produces goods:

$$
Y_{t}(k)=A_{t} L_{t}(k)
$$

where $A_{t}$ is total factor productivity. Demand for the k-th firm's goods is given by equation ${ }^{8}$

$$
Y_{t}(k)=\left(\frac{P_{t}^{H}(k)}{P_{t}^{H}}\right)^{-\frac{1}{v_{H}}} Y_{t}
$$

where $P_{t}^{H}(k)$ is the price set by the $k$-th firm, and $P_{t}^{H}$ is the price of domestic goods, $Y_{t}$ is aggregate demand for domestic goods in the economy, and $v_{H}$ is the elasticity of substitution between domestic goods.

Firms maximize discounted real profit made up of revenue $\frac{P_{t}^{H} Y_{t}(k)}{P_{t}^{c p i}}$ less the costs of labor $\frac{W_{t} L_{t}(k)}{P_{t}^{c p i}}$ and price adjustment $\frac{k_{H}}{2}\left(\frac{P_{t}^{H}(k)}{P_{t-1}^{H}(k)}-\left(\pi_{t-1}^{H}\right)^{\iota_{H}}\left(\pi_{*}\right)^{1-\iota_{H}}\right)^{2} \frac{P_{t}^{H} Y_{t}}{P_{t}^{c p i}}$

Firms bear quadratic costs if price changes depart from the predefined level $\left(\pi_{t-1}^{H}\right)^{\iota_{H}}\left(\pi_{*}\right)^{1-\iota_{H}}$. This method of introducing rigidities into a firm's pricing policy decision-making is described in Rotemberg (1982). ${ }^{9}$ In setting prices under Rotemberg, discounted profit is written as

\footnotetext{
${ }^{8}$ For a more detailed description of the demand function, see, for instance, Walsh (2010).

${ }^{9}$ An alternative to this method often used in DSGE models is a situation where firms can set prices without costs. However, in each period, a firm with a certain probability optimizes its behavior (see Calvo, 1983), and where it does not, it sets prices under a predefined rule. Both of these rules yield identical equations in loglinearized model.
} 


$$
E_{t} \sum_{i=0}^{\infty} \lambda_{t+i}\left(\begin{array}{c}
\frac{P_{t+i}^{H}(k)}{P_{t+i}^{c p i}} Y_{t+i}(k)-\frac{W_{t+i}}{P_{t+i}^{c p i}} L_{t}(k)- \\
\frac{k_{H}}{2}\left(\frac{P_{t+i}^{H}(k)}{P_{t+i-1}^{H}(k)}-\left(\pi_{t-1}^{H}\right)^{\iota_{H}}\left(\pi_{*}\right)^{1-\iota_{H}}\right)^{2} Y_{t+i} \frac{P_{t+i}^{H}}{P_{t+i}^{c p i}}
\end{array}\right)
$$

where $\lambda_{t}$ is a discount factor used by a firm, $k_{H}$ is a coefficient for the deviation of prices for domestic goods from the desired predefined level, $\iota_{H}$ is the weight of lagged value in the desired prededefined level of prices for domestic goods, and $\pi^{*}$ is the inflation target $\pi_{t}^{H}=\frac{P_{t}^{H}}{P_{t-1}^{H}}$.

The first order condition is the supply curve, often referred to as the Phillips curve:

$$
\begin{aligned}
& \left(1-\frac{1}{v_{H}}\right)+\frac{1}{v_{H}} \frac{W_{t}}{A_{t} P_{t}^{c p i}} \frac{1}{p_{t}^{H}}-k_{H}\left(\pi_{t}^{H}-\left(\pi_{t-1}^{H}\right)^{\iota_{H}}\left(\pi_{*}\right)^{1-\iota_{H}}\right) \pi_{t}^{H}+ \\
& \qquad k_{H} \beta E_{t}\left(\frac{C_{t}-h C_{t-1}}{C_{t+1}-h C_{t}}\left(\pi_{t+1}^{H}-\left(\pi_{t}^{H}\right)^{\iota_{H}}\left(\pi_{*}\right)^{1-\iota_{H}}\right)\left(\frac{\pi_{t+1}^{H}}{\pi_{t+1}}\right)^{2} \pi_{t+1} \frac{Y_{t+1}}{Y_{t}}\right)=0 \\
& \text { where } \pi_{t}=\frac{P_{t}^{c p i}}{P_{t-1}^{c p i}} \text { and } p_{t}^{H}=\frac{P_{t}^{H}}{P_{t}^{c p i}}
\end{aligned}
$$

\section{Importer firms}

The purpose of importer firms is similar to that of domestic firms, but, instead of producing goods, they buy goods in foreign countries, reselling them at higher prices. In this case, the $k$-th firm's labor cost is replaced by the cost of purchasing goods:

$$
\mathcal{E}_{t} \frac{P_{t}^{F^{*}}}{P_{t}^{c p i}} \operatorname{Im}_{t}(k)
$$

where $\operatorname{Im}_{t}(k)$ is the quantity of goods imported by the $k$-th firm, and $P_{t}^{F^{*}}$ is the price level of foreign goods, $\pi_{t}^{F}=\frac{P_{t}^{F}}{P_{t-1}^{F}}$. Similarly to domestic firms, importer firms bear quadratic costs of price adjustment, $\frac{k_{F}}{2}\left(\frac{P_{t}^{F}(k)}{P_{t-1}^{F}(k)}-\left(\pi_{t-1}^{F}\right)^{\iota_{F}}\left(\pi_{*}\right)^{1-\iota_{F}}\right)^{2} \frac{P_{t}^{F} I m_{t}}{P_{t}^{c p i}}$. Revenue is defined as price $P_{t}^{F}(k)$, multiplied by sales $\operatorname{Im}_{t}(k)$. Given the import demand function, profit is defined as

$$
E_{t} \sum_{i=0}^{\infty} \lambda_{t+i}^{i}\left(\begin{array}{l}
\frac{P_{t+i}^{F}(k)}{P_{t+i}^{c p i}} I_{t+i}(k)-\mathcal{E}_{t+i} \frac{P_{t+i}^{F^{*}}}{P_{t+i}^{c p i}} \operatorname{Im}_{t+i}(k)-\frac{k_{F}}{2} \\
\left(\frac{P_{t+i}^{F}(k)}{P_{t+i-1}^{F}(k)}-\left(\pi_{t-1}^{F}\right)^{\iota}\left(\pi_{*}\right)^{1-\iota_{F}}\right)^{2} \operatorname{Im}_{t+i} \frac{P_{t+i}^{F}}{P_{t+i}^{c p i}}
\end{array}\right)
$$


The first order conditions are then similar to that for domestic firms and constitutes import supply:

$$
\begin{aligned}
& \left(1-\frac{1}{v_{F}}\right)+\frac{1}{v_{F}} \operatorname{rer}_{t} \frac{1}{p_{t}^{F}}-k_{F}\left(\pi_{t}^{F}-\left(\pi_{t-1}^{F}\right)^{\iota_{F}}\left(\pi_{*}\right)^{1-\iota_{F}}\right) \pi_{t}^{F}+ \\
& k_{F} \beta E_{t}\left(\frac{C_{t}-h C_{t-1}}{C_{t+1}-h C_{t}}\left(\pi_{t+1}^{F}-\left(\pi_{t}^{F}\right)^{\iota_{F}}\left(\pi_{*}\right)^{1-\iota_{F}}\right)\left(\frac{\pi_{t+1}^{F}}{\pi_{t+1}}\right)^{2} \pi_{t+1} \frac{I m_{t+1}}{I m_{t}}\right)=0
\end{aligned}
$$

where $r e r_{t}$ is the real exchange rate given by $r e r_{t}=\frac{\varepsilon_{t} P_{t}^{F^{*}}}{P_{t}^{c p i}}, v_{F}$ is the elasticity of substitution between imported goods, $I m_{t}$ - aggregate demand for imported goods, $k_{F}$ is a coefficient for the deviation of prices for domestic goods from the predefined level, $\iota_{F}$ is the weight of lagged value in the prededefined level of prices for domestic goods.

\section{Aggregating firms}

Aggregating firms aggregate domestic goods $Y_{t}$ and impsorted goods $I_{t}$ into final consumption goods:

$$
C_{t}=A^{*}\left(Y_{t}\right)^{\gamma}\left(I m_{t}\right)^{1-\gamma}
$$

where $A^{*}$ is an equivalent of total factor productivity for aggregating firms, and $\gamma$ is the elasticity of final consumption goods with respect to domestic goods in aggregating firms' production function.

A firm seeks to obtain the largest possible quantity of final consumption goods under fixed costs of production inputs. The budget constraint for this task can be written as

$$
P_{t}^{H} Y_{t}+P_{t}^{F} I m_{t}=P_{t}^{c p i} C_{t}=\text { const }
$$

The solution of the optimization problem is aggregated demand function for domestic and imported goods:

$$
\begin{gathered}
p_{t}^{H} Y_{t}=\gamma C_{t} \\
p_{t}^{F} I m_{t}=(1-\gamma) C_{t}
\end{gathered}
$$

\section{Trade balance and risk premium}

Net foreign assets, $\left(R_{t}^{*} r p\left(b_{t}^{*}, p_{t}^{o i l}, z_{t}^{R P}\right)\right)^{-1} \mathcal{E}_{t} B_{t}^{*}$ are made up of net foreign assets of the previous period $E_{t} B_{t-1}^{*}$, export earnings $E_{t} p^{\text {oil }}{ }_{t} P^{F^{*}} X_{t}$ less imports $E_{t} P^{F^{*}}{ }_{t} m_{t}$, and change in reserves $\mathcal{E}_{t} P^{F^{*}} d$ Res : 


$$
\begin{gathered}
\left(R_{t}^{*} r p\left(b_{t}^{*}, p_{t}^{\text {oil }}, z_{t}^{R P}\right)\right)^{-1} \varepsilon_{t} B_{t}^{*}=\varepsilon_{t} B_{t-1}^{*}+\varepsilon_{t} p_{t}^{\text {oil }} P_{t}^{F^{*}} X_{t}- \\
\varepsilon_{t} P_{t}^{F^{*}} \operatorname{Im}_{t}-\varepsilon_{t} P_{t}^{F^{*}} d \operatorname{Res}_{t}
\end{gathered}
$$

where $X_{t}$ is exports, all of which are assumed to be oil and exogenous, $d R e s_{t}$ is a variable for change in reserves.

As in Schmitt-Grohe and Uribe (2003), a risk premium is introduced to guarantee a single stationary equilibrium under trends given in the model. Also, we assume that the risk premium is negatively related to the oil price. The resulting risk premium can then be written as

$$
r p\left(b_{t}^{*}, p_{t}^{o i l}, z^{R P}\right)=r p_{s} e^{a_{d}\left(\ln b_{t}^{*}-\ln b_{s}^{*}\right)-a_{d} a_{o i l}\left(\ln p_{t}^{o i l}-\ln p_{s}^{o i l}\right)+z_{t}^{R P}+\text { higher order terms }}
$$

where $z_{t}^{R P}$ is the exogenous part of the risk premium, $a_{d}$ and $a_{d} a_{\text {oil }}$ are asset and oil elasticities at point $\left(b_{s}{ }^{*}, p_{s}{ }^{\text {oil }}, 0\right)$, and $r p_{s}$ is the risk premium value at point $\left(b_{s}^{*}, p_{s}^{\text {oil }}, 0\right)$.

\section{Central bank}

This study uses two monetary policy regimes - that of the fixed and that of the floating exchange rate. Regardless of the exchange rate regime assumed in the model, interest rate policy is defined by the rule

$$
\frac{R_{t}}{R_{*}}=\left(\frac{R_{t-1}}{R_{*}}\right)^{\phi_{R}}\left(\frac{E_{t}\left(\pi_{t} \pi_{t+1} \pi_{t+2} \pi_{t+3}\right)^{0.25}}{\pi_{*}}\right)^{\left(1-\phi_{R}\right) \phi_{\pi}} \exp ^{e_{t}^{R}}
$$

where $e_{t}^{R}$ is a monetary policy shock, $\phi_{R}$ is the inertia coefficient of the interest rate under in the monetary policy rule, $\phi_{\pi}$ the coefficient of the interest rate's response to expected inflation in the monetary policy rule, $R_{*}$ is the steady state interest rate, and, $\pi_{*}$ is the inflation target.

Under the fixed exchange rate regime, the rule for exchange rate targeting ${ }^{10}$ is given by

$$
r e r_{t}=\exp ^{z_{t}^{\mathcal{E}}} r e r_{s s, t}
$$

Under the floating exchange rate regime, the central bank does not influence the exchange rate, and reserves change is described by the following equation:

$$
d \operatorname{Res}_{t}=\left(\exp ^{z_{t}^{\varepsilon}}-1\right) \frac{1}{A_{t} P_{t}^{c p i}}
$$

where $r e r_{s s, t}$ is the steady state real exchange rate in period $t, z_{t}^{\varepsilon}$ is an exogenous process in the rule for the exchange rate change (and the change in

\footnotetext{
${ }^{10}$ Hereinafter, we refer to this regime as the fixed exchange rate.
} 
reserves equation). Although the process is in both cases denoted identically and has an effect on the currency market, the implications are in each case different. In the floating exchange rate model, this process directly changes reserves, whereas in the fixed rate model this occurs via the implicit rule for change in reserves which emerges from (12a).

We should make a point that targeting the real exchange rate does not imply maintaining it at a certain level from period to period. Here targeting means keeping the exchange rate in line with the current oil price, i.e., on a level which would be set in the long run in the absence of shocks.

Modeling the fixed exchange rate is conventionally understood to involve a number of technical difficulties. In this model, the assumption of maintaining a fixed exchange rate implies departing from fundamental long-term levels throughout the period of maintaining the exchange rate, which would mean the economy's constant deviation from an equilibrium.

This economy could be modeled similarly to the ZLB (zero lower bound) technique in Kulish et al. (2014), but this involves additional assumptions that agents would expect the exchange rate regime to be maintained for a long time. Given the requirement for these assumptions and a number of additional technical difficulties, we have decided against this method, following a more conventional approach of targeting the departure of the real exchange rate from an equilibrium.

Polbin (2014) proposed an alternative rule for modeling the monetary policy regime. The author assumes that the deviation of the exchange rate from the trend follows a random walk, with which the paper replaces interest rate equations and the exchange rate rule. Reducing the number of variables, the author eliminates change in reserves from the model, which means maintaining fixed exchange rate policy via interesting rates rather than by way of reserves policy.

For the purposes of this study, however, the definition of the monetary policy rule and the rule change in reserves only matters because it exerts certain influence on the model's structure and, consequently, on its predictive power. Meanwhile, a number of additional experiments, which are not presented in this paper for space considerations, have suggested that the replacement of expected inflation with current inflation in the monetary policy rule does not cause the results to change substantially, while a different rule for reserves does bring about changes. The study considers just two reserves rule definitions, which represent the fixed real exchange rate and the absence of the rule for the exchange rate. The latter corresponds to the floating exchange rate regime, introduced late in 2014, while the former was chosen out of a number of alternative rules for the exchange rate, with the model's predictive power and uniqueness of its solution taken into account. 


\section{Exogenous processes}

There are five exogenous processes in the model in addition to those described above. The technology process

$$
\begin{gathered}
\log A_{t}=g+\log A_{t-1}+\log z_{t}^{A} \\
\log z_{t}^{A}=\rho_{z} \log z_{t-1}^{A}+e_{t}^{Z}
\end{gathered}
$$

where the second equation is the definition of the process, $z_{t}^{A}, g$ is a permanent rate of technology process growth, $\rho_{z}$ is the autocorrelation coefficient of a technology shock, $e_{t}{ }^{z}$ is a technology shock. The exogenous part of the risk premium is given by

$$
z_{t}^{R P}=\rho_{R P} Z_{t-1}^{R P}+e_{t}^{R P}
$$

where $\rho_{R P}$ is the autocorrelation coefficient of a risk-premium shock, and $e_{t}{ }^{R P}$ is a risk-premium shock. The behavior of the exogenous process responsible for change in reserves and exports is defined by the following two equations:

$$
\begin{aligned}
z_{t}^{\mathcal{E}} & =\rho_{e} z_{t-1}^{\mathcal{E}}+e_{t}^{\mathcal{E}} \\
\log \frac{X_{t}}{A_{t}} & =\rho_{X} \log \frac{X_{t-1}}{A_{t-1}}+e_{t}^{X}
\end{aligned}
$$

where $\rho_{e}$ and $\rho_{X}$ are the autocorrelation coefficients of reserves and exports shocks, $e_{t}^{E}$ is a reserves shock, and $e_{t}^{X}$ is an exports shock.

We also assume that real oil price fluctuations are given by the equation

$$
\log p_{t}^{o i l}=\log p_{t-1}^{o i l}+e_{t}^{o i l}
$$

where $e_{t}{ }^{\text {oil }}$ is an oil price shock. ${ }^{11}$

In effect, we assume that there are two stochastic trends in the economy: a technology trend $\left(A_{t}\right)$, and an oil trend $\left(p_{t}^{\text {oil }}\right)$. All the other exogenous processes return to their mean(s) after a one-off shock.

For simplicity, the variables for the foreign interest rate and foreign inflation were taken as constants. Annualized inflation was taken to be $2 \%$, the interest rate was taken as $3.5 \%$.

\section{Model solution and estimation}

The study uses the loglinear approximation of the model. The model contains two unit roots but cannot be normalized in a standard manner. Because of it, the loglinearization relies on the technique described in Kim et al. (2008) and Lan and Meyer-Gohde (2014).

\footnotetext{
${ }^{11}$ All the shocks are assumed to be normally distributed and independent.
} 
Model solution and estimation is conducted in the Dynare software package (Adjemian et al., 2011), but the application of the proposed algorithms results in the emergence of a nonstationary model (a model with unit roots), causing problems for conventional implementation. Appendix B presents an alternative implementation which can be used with the Dynare package.

To match the model to the data, six time series are employed, spanning the period from 2003Q2 to 2015Q3 or 2013Q1, depending on the model. ${ }^{12}$ Estimation uses change in the logarithm of real GDP $d \log y_{t}^{o b s}$ change in the logarithm of real exports $d \log x_{t}^{o b s}$, change in the logarithm of the CPI $\log \pi_{t}^{o b s}$, the interest rate (the average overnight MIACR) $\log R_{t}^{o b s}$, change in the ruble exchange rate to the dollar $\log \left(\frac{\varepsilon_{t}^{o b s}}{\varepsilon_{t-1}^{o b s}}\right)$, and change in the oil price in real terms ${ }^{13} \log \left(\frac{p_{t}^{o i l, o b s}}{p_{t-1}^{o i l, o b s}}\right)$.

That said, in addition to the six shocks of the model, the equations linking the observations to the model include five measurement errors ${ }^{14}$ and are given by

$$
\begin{gathered}
d \log y_{t}^{o b s}=g+z_{t}^{A}+\frac{C}{Y}\left(c_{t}-c_{t-1}+d c_{t, s s}\right)+\frac{X}{Y}\left(x_{t}-x_{t-1}\right)- \\
\frac{I M}{Y}\left(i m_{t}-i m_{t-1}+d i m_{t, s s}\right)+e_{t}^{y, o b s}, \\
d \log x_{t}^{o b s}=g+z_{t}^{A}+\left(x_{t}-x_{t-1}\right)+e_{t}^{x, o b s}, \\
\log \pi_{t}^{o b s}=\log \pi_{s s}+\pi_{t}+e_{t}^{\pi, o b s}, \\
\log R_{t}^{o b s}=4\left(\log R_{s s}+R_{t}\right)+e_{t}^{R, o b s}, \\
\log \left(\frac{\mathcal{E}_{t}^{o b s}}{\mathcal{E}_{t-1}^{o b s}}\right)=g_{s s}^{\varepsilon}+g_{t}^{\varepsilon}+e_{t}^{g^{\varepsilon}, o b s}, \\
\log \left(\frac{p_{t}^{o i l, o b s}}{p_{t-1}^{o i l o b s}}\right)=e_{t}^{o i l}
\end{gathered}
$$

where $e_{t}^{y, o b s}, e_{t}^{x, o b s}, e_{t}^{\pi, o b s}, e_{t}^{R, o b s}, e_{t}^{g \varepsilon, o b s}$ are measurement errors for the following variables with standard deviations of $0.003,0.008,0.004,0.01$, and $0.02 .{ }^{15}$ The parameters with index $s s$ denote the steady states of the variables, while the lower-case variables define the detrended upper-case variables.

\footnotetext{
12 This is only done for the preliminary analysis of the models and implies a shift, in 2014, to the floating exchange rate. This aims to eliminate the impact of the 2014 and 2015 data on the parameter estimates of the model with the fixed exchange rate. The forecasts are compared on identical samples.

${ }^{13}$ The inflation, GDP and export numbers were seasonally adjusted. That said, when the CPI is subsequently used in estimation, we just sum seasonally adjusted growth rates. We use data available as of February 2016.

${ }^{14}$ We do not add measurement errors to the oil price, as this effectively fails to improve the models' predictive power.

15 These standard deviations define variances that range from several percent to tens of percent, which is normal for this model class.
} 
Ratios $\frac{C}{Y}, \frac{X}{Y}$, and $\frac{I M}{Y}$ describe equilibrium relationships between nominal consumption, exports and GDP.

The results forecasted are not sensitive to changes in the variance of measurement errors in the range from several percent to tens of percent. For instance, if we take all observation measurement error variances to be $10 \%$ of a parameter variance, the average forecast error increases by $2-3 \%$ for a model with the fixed exchange rate. As the results are insensitive to these parameters, we do not care to select them more thoroughly.

We estimate the model based on Bayesian statistic. This study employs the standard Metropolis-Hastings algorithm with an auxiliary normal density (after the optimization, the inverse Hessian is used as a covariance matrix). We retain 50000 iterations, the first half of which is excluded. For more details and alternative estimation methods, see Herbst and Schorfheide (2015) and FernandezVillaverde et al. (2016).

Tables $1 \mathrm{a}$ and $1 \mathrm{~b}$ in Appendix A show prior parameter distributions. The majority of distributions selected are close to standard for this model type. Prior distributions for coefficients before the mark-ups $\left(k_{н}\right.$ и $\left.k_{F}\right)$ are taken from Aruoba et al. (2016). This study also employs a model without capital. The prior distribution of the autocorrelation coefficient of a technology shock is also taken from the above model. The rest of the shocks of our model are not found in Aruoba et al. (2016), and we therefore use a standard approach for them, choosing beta-distributions with autocorrelation coefficients of 0.5-0.7 (see, for instance, Cristofel et al., 2008). We set the distribution of the coefficient of habit formation in consumption $(h)$ similar to Cristoffel et al. (2008). The coefficients of interest rate inertia and its response to inflation in the monetary policy rule are also close to conventional. We hold no specific beliefs regarding the weights of lagged value in the predetermined price levels of domestic and imported goods $\left(\iota_{H} И \iota_{F}\right)$, except that these weights should lie within the range from 0 to 1 , hence we set a beta distribution with a mean of 0.5 for them. Quarterly growth rates for a steady state economy $(g)$ and coefficient inverse to elasticity of labor supply $(\phi)$ are usually calibrated, but in order to improve the model's flexibility, they are also estimated in this study. The standard value of coefficient inverse to elasticity of labor supply $(\phi)$ is 2 , and we therefore assume it to be the mean for a normal distribution with a dispersion of 1 . The mean for the distribution of quarterly economic growth rates $(g)$ is taken to be $0.5 \%$, which is less than average for the period in question but is roughly in line with the estimates of the Russian economy's long-term growth.

Mean prior distributions for the standard deviations of shocks are calibrated at no more than $0.5 \%$ per quarter. As such, for shocks directly related to interest rates, i.e., a monetary policy shock and a risk premium shock, the mean annual values are $1 \%$ and $0.5 \%$. The means for total factor productivity and exports shocks are taken to be $0.5 \%$ per quarter, for an oil price shock model they equal $10 \%$. 
As mentioned above, the two models (with two different exchange rate regimes) differ in the interpretation of a shock related to the exchange rate (and change in reserves), and we therefore assign different prior distributions for this shock. The mean for a shock in the fixed exchange rate model is taken as $0.5 \%$ per quarter, and that for the floating exchange rate model - as $0.1 \%$. The latter reflects the fact that there are often no interventions at all under the floating exchange rate. Such a liberal choice of means for standard deviations is compensated by a wider dispersion for prior distributions.

The means for risk-premium parameters $\left(a_{d}\right.$ and $\left.a_{\text {oil }}\right)$ are selected based on the considerations set forth below. If debt changes by $10 \%$, interest rates should change by several percentage points. As the criterion outlined above is not explicit enough, a prior distribution with a large dispersion is imposed on the debt elasticity of the risk premium. Also, it is assumed that a 10-percent change in the oil price causes a lesser risk premium change than a 10-percent change in debt. A prior distribution for the ratio of oil and debt elasticity $\left(a_{d} a_{\text {oil }}\right.$ and $\left.a_{d}\right)$ is chosen from this perspective. For the model with the floating exchange rate, distribution for $a_{d}$ was taken to be the same as for the model with the fixed exchange rate. However, the model for the floating exchange rate showed to be sensitive to the choice of a prior distribution for the debt elasticity of a risk premium $\left(a_{d}\right)$. Under the same distribution as that for the model with the fixed exchange rate, the model with the floating exchange rate produces unreasonable forecasts, so we choose a lower mean and look further at the results of two forecasts (see the discussion below). We also note that additional simulations show the results of the model with the fixed exchange rate to be insensitive to this parameter.

Constants $\frac{X}{Y}$ and $\frac{I M}{Y}$ are calibrated at levels of 0.3 and 0.22 . These values were obtained as average for the period in which the oil price stood just above $\$ 100$ per barrel. We chose this particular period because the linearization is applied in the neighbourhood of that point. The averages for the entire period, $\frac{X}{Y}$ and $\frac{I M}{Y}$, are equal to 0.3 and 0.21 respectively, which is close to the values used. Parameter $\beta$ was chosen so that the equilibrium real interest rate would stand at $3.5 \%$. The equilibrium interest rate in the model is $4 \% .^{16}$

\section{Results}

As mentioned above, the aim of this study is to test the predictive power of the DSGE models presented. However, to get a better insight into their properties, we show more characteristics traditionally demonstrated with respect to this model class.

We estimated the model with the fixed exchange rate for the period spanning from 2003Q2 to 2013Q17 and the model with the floating exchange rate for

\footnotetext{
${ }^{16}$ For the calibration parameters, see Table 2 in Appendix A.

${ }^{17}$ A prior distribution with a mean of 0.03 was taken for parameter $a_{d}$.
} 
the 2003Q2 - 2015Q3 time span. The parameters of posterior distributions are presented in Tables 1a and 1b in Appendix A. Figures 2 and 3 in Appendix A show impulse responses to a shock of oil prices of $10 \%$ for output, inflation, an interest rate, and change in the exchange rate in both models. ${ }^{18}$ These responses are compared in Figure 4 in Appendix A. For output, inflation, and the exchange rate, Figure 4 shows accumulated transformations of mean responses, for the interest rate - the mean response of the level. The responses in the model with the fixed exchange rate shows to be much weaker than that in the model with the floating rate on the horizon indicated above. The impact on GDP after 10 quarters is estimated at $0.65 \%$ for the model with the fixed exchange rate and at $2 \%$ for that with the floating exchange rate. The same values for the price level are equal to $1 \%$ and $3.7 \%$ respectively, standing at $6 \%$ and $19 \%$ for the exchange rate.

We should also point out a specific feature of the model with the fixed exchange rate. The observable variables do not respond to a risk premium shock. This occurs because in maintaining a long-term equilibrium of the real exchange rate, the central bank reduces to naught risk premium shocks by changing reserves.

Therefore, the risk premium shock in the equation for the interest rate parity (equation 2) turns out to be compensated by change in the debt level, while in the equation for the balance of payments (equation 10), an additional change in debt is balanced out by change in reserves. Thus, equations for change in all the other variables remain unchanged and, consequently, the exchange rate remains constant. The exports shock behaves in a similar manner, but it has an impact on both exports themselves as an observable variable and GDP as its component. The impact of the other shocks is shown in Figure $5^{19}$ in Appendix A.

Throughout this period, the total factor productivity shock was making the principal contribution to GDP performance, exerting downward pressure on inflation and interest rates (except for late 2008 and early 2009). As inflation decomposition shows, interest rates were not high enough to bring inflation to an equilibrium level. ${ }^{20}$ The monetary policy shock acted as a major inflation determinant and also affected the nominal exchange rate because the real exchange rate remained fixed and affected the interest rate. Oil price movements, on the average, helped the exchange rate to strengthen, but at times (as the oil price dropped), caused it to weaken. This, to a certain extent, translated into prices and hence into the interest rate. Exchange rate policy also made a mostly disinflationary contribution.

\footnotetext{
${ }^{18}$ In the text below, change means the difference of logarithms multiplied by 100 , the interest rate means $100 \log \left(1+i_{t}\right)$, inflation means $100 \log \left(1+\pi_{t}\right)$.

${ }^{19}$ We note that decomposition is given under specific parameters, with decomposition into shocks only shown under these particular parameters (and "mean" shocks). Under the Bayesian concept, parameters have a certain distribution, and hence so does the decomposition. Also, the decomposition obtained shows the interpretation of the model's shocks, which may be wrong because of the model's incorrect specification.

${ }^{20}$ This results from setting the model's target at 4\%, which disagrees with reality. But as this study's main goal was forecasting rather than interpretation of the model's results, we leave a substantive discussion about the choice of parameters for future papers.
} 
Figures 5 and 6 in Appendix A present the decomposition into shocks for both models under the modal values of parameters. Total factor productivity was the main growth determinant in the model with the fixed exchange rate. Meanwhile, in the model with the floating exchange rate, growth was additionally determined by the oil price and the currency market shock. But the interest rate - inflation pair was found to be the most interesting for comparison. While the contributions of monetary policy shocks to inflation are relatively similar, they make virtually no contribution to the interest rate in the model with the floating range, which seems strange. Figure 7 in Appendix A shows a clearer picture of this. In the model with the fixed exchange rate, a 1-percentage-point rise in interest rates results in an inflation acceleration of no more than $0.5 \%$ in the next four quarters, while in the model with the floating exchange rate, inflation responds by going up 1.5\%. Given this sizable difference and comparing these responses with those to similar shocks in studies regarding other countries (Cristoffel et al., 2008; Christiano et al., 2010; and Adolfson et al., 2013), we draw the conclusion that the economy's response to the monetary policy shock for the model with the floating exchange rate is different in magnitude from responses in models for other countries.

Also, we compared the models' marginal densities, which represent the probabilities of obtaining observable data, had they been generated by this model. While we are aware that the parameter sets were different, we compute marginal densities for 40 and 50 observations for each of the models and then compare them. It can be seen from Table 3 that both estimates of marginal densities for each of the sample periods show higher values in the model with the fixed exchange rate.

To sum up briefly the comparison of the models with the fixed and floating exchange rate, we note that the model with the fixed exchange rate better agrees with the actual economic situation in the period under examination, showing less volatile decompositions into shocks and more conventional impulse responses. The model with the fixed exchange rate also shows higher marginal densities. Although these characteristics of the models are illustrative, all this does not guarantee the model with the fixed exchange rate a better predictive power and does not allow comparison with the BVAR model, so we proceed to considering mean-root-square errors of the forecast.

\section{Mean square errors}

Here we compare forecasts ${ }^{21}$ for six periods, beginning from 2010Q3, for output growth, price and exchange rate rises, as well as those for output, prices, the exchange rate and interest rates, under the given oil price. Ratios of mean square errors (MSE) of the forecasts are presented in Tables $4 a-4 b^{22}$ in Appendix A.

\footnotetext{
${ }^{21}$ Modal forecasts for DSGE and mean forecasts for BVAR are used. The use of mean forecasts for DSGE does not change the results appreciably (the comparison was conducted for the model with the fixed exchange rate).

${ }^{22}$ No formal tests for the statistical significance of RMSE differences in the spirit of Diebold and Mariano (1995) were conducted, as the sample period was too short.
} 
It can be seen from Table $4 \mathrm{a}$ that the model with the floating exchange rate is less accurate than that with the fixed exchange rate. This, however, stems from the model's excessive sensitivity to prior distributions. For instance, impulse responses to the oil price shock only change sign at the 50-th point (the last of the forecast points), resulting in, among other things, GDP growth in the initial periods after an oil price drop (see Figures 8-10 in Appendix A). To avoid this kind of situation, we change the first parameter of a prior distribution for $a_{d}$ to 0.01 . Table $4 \mathrm{~b}$ shows MSE ratios between this model and the model with the fixed exchange rate. The model with the floating exchange rate is found to be the best for forecasting GDP, while the model with the fixed rate best serves the purpose of forecasting the exchange rate. The interest rate forecast is clearly the most accurate in the model with the floating exchange rate. The other relationships are not so obvious and require formal tests, which were not performed as part of this study. ${ }^{23}$

In addition, the predictive power of the models is compared with that of the BVAR model. The same six variables are used to construct a BVAR model with prior distributions, as in Giannone et al. (2015), which showed to be fairly effective, including for Russian data (see Deryugina and Ponomarenko, 2015). It is easy to see from Table 4 that BVAR is superior to the model with the fixed exchange rate as regards GDP, but inferior with respect to all other indicators. Moreover, for a GDP forecast, the BVAR model is comparable with the alternative model with the floating exchange rate.

As mentioned in the Introduction, BVAR models have showed themselves as a better forecasting tool for other countries than DSGE models, but our results suggest that this conclusion does not apply to the DSGE and BVAR model specifications examined in this study. While taking into account all the reservations made in the Introduction and bearing in mind that the findings of this study and the results of Malakhovskaya (2016) are not fully comparable, we point out that the author of the latter draws the same conclusions regarding the Russian data as we do.

\section{Conclusion}

This study examines a number of small-scale structural linear models for the Russian economy. Despite all the problems associated with a strong dependence on prior values and incorrect specification, these models are not inferior to BVAR models as regards their predictive power and are superior for some indicators. Thus, comparison with the same-scale BVAR model suggests that under a given oil price DSGE models presented in this study are superior as regards forecasting the exchange rate, prices, and the interest rate, and comparable in forecasting GDP.

Appendices are available at www.cbr.ru/money-and-finance

\footnotetext{
${ }^{23}$ Results for all the other criteria (marginal density, decomposition and impulse responses) only change numerically upon change in prior distribution for $a_{d}$.
} 


\section{References}

Adjemian, A., Bastani, H., Juillard, M., Mihoubi, F., Perendia, P., Ratto, M. and Villemot, S. (2011). Dynare: reference manual, version 4 // Dynare Working Papers. 2011. № 1.

Adolfson, M., Laséen, S., Christiano, L., Trabandt, M. and Walentin, K. (2013). Ramses II - model description. Sveriges Riksbank, Occasional Paper Series, 12.

Aruoba, B., Cuba-Borda, P., Schorfheide, F. (2016). Macroeconomic dynamics near the ZLB: A tale of two countries, [Manuscript].

Burgess, S., Fernandez-Corugedo, E., Groth, C., Harrison, R., Monti, F., Theodoridis, K., Waldron, M. (2013). The Bank of England's forecasting platform: COMPASS, MAPS, EASE and the suite of models. Bank of England, Staff Working Paper, 471.

Calvo, G. (1983). Staggered prices in a utility-maximizing framework. Journal of Monetary Economics, 12(3), pp. 383-398.

Christiano, L., Rostagno, M. and Motto, R. (2010). Financial factors in economic fluctuations. ECB Working Papers 2010, 1192.

Christoffel, K., Coenen, G. and Warne, A. 2008. The new area-wide model of the Euro area: A micro-founded open-economy model for forecasting and policy analysis. ECB Working Papers, 944.

Del Negro, M., Hasegawa, R. and Schorfheide, F. (2016) Dynamic prediction pools: An investigation of financial frictions and forecasting performance. Journal of Econometrics, 191(2), pp. 391-405.

Deryugina, E. and Ponomarenko, A. (2015). Large Bayesian Vector Autoregression Model for the Russian economy. [In Russian]. The Central Bank of the Russian Federation, Working Paper Series, 1.

Diebold, F. and Mariano, R. (1995). Comparing predictive accuracy. Journal of Business and Economic Statistics, 13, pp. 253-265.

Diebold, F., Schorfheide F. and Shin, M. (2016). Real-time forecast evaluation of DSGE models with stochastic-volatility. Manuscript, University of Pennsylvania.

Domit, S., Monti, F. and Sokol A. (2016). A Bayesian VAR benchmark for COMPASS. Bank of England, Staff Working Paper, 583.

Edge, R. and Gurkaynak, R. (2010). How useful are estimated DSGE model forecasts for central bankers? Brookings Papers on Economic Activity, Economic Studies Program, 41(2), pp. 209-259. The Brookings Institution.

Fernandez-Villaverde, J., Gordon, G., Guerron-Quintana, P. and Rubio-Ramirez, J. (2015). Nonlinear adventures at zero lower bound. Journal of Economic Dynamics and Control, 57, pp. 182-204.

Fernandez-Villaverde, J., Rubio-Ramirez, J. and Schorfheide, F. (2016). Solution and estimation methods for DSGE models. In: Handbook of Macroeconomics. Vol. 2. (preliminary draft).

Giannone, D., Lenza, M. and Primiceri, G. (2015). Prior selection for vector autoregressions. The Review of Economics and Statistics, 97(2), pp. 436-451.

Gorodnichenko, Y. and Ng, S. (2010). Estimation of DSGE models when the data are persistent. Journal of Monetary Economics, 57(3), pp. 325-340.

Herbst, E. and Schorfheide, F. (2015). Bayesian estimation of DSGE models. Princeton University Press.

Iversen, J., Laséen, S., Lundvall H. and Soderstrom, U. (2016). Real-time forecasting for monetary policy analysis: The case of Sveriges Riksbank. Sveriges Riksbank Working Paper Series, 318. 
Kim, J., Kim, H., Schaumburg, E. and Sims, C. (2008). Calculating and using secondorder accurate solutions of discrete time dynamic equilibrium models. Journal of Economic Dynamics and Control, 32, pp. 3397-3414.

Korinek, A. (2015). Thoughts on DSGE macroeconomics: matching the moment, but missing the point? In: Paper for Conference «A Just Society» honoring Joseph Stiglitz's 50 years of teaching.

Kulish, M., Morley, J. and Robinson, T. (2014). Estimating DSGE models with forward guidance. Discussion paper 2014-23, School of Economics, The University of New South Wales.

Lan, H. and Meyer-Gohde, A. (2014). Solvability of perturbation solutions in DSGE models. Journal of Economic Dynamics and Control, 45, pp. 366-388.

Linde, J., Smets, F. and Wouters, R. (2015). Challenges for macro models used at central banks. In: Handbook of Macroeconomics. Vol. 2. (preliminary and incomplete draft).

Lubik, T. and Matthes, C. (2014). Indeterminacy and learning: an analysis of monetary policy in the great inflation. FRB of Richmond Working Paper, 14-02.

Malakhovskaya, O. (2016). Use of DSGE models for forecasting: an outlook. [In Russian]. Voprosy Ekonomiki, 12, pp. 129-146.

Maliar, L., and Maliar, S. (2015). Merging simulation and projection approaches to solve high-dimensional problems with an application to a new Keynesian model. Quantitative Economics, 6, pp. 1-47.

Muller, U. (2012). Measuring prior sensitivity and prior informativeness in large Bayesian models. Journal of Monetary Economics, 59, pp. 581-597.

Polbin, A. (2014). Econometric evaluation of a structural macroeconomic model for the Russian economy. Applied Econometrics, 33(1), pp. 3-29.

Rotemberg, J. (1982). Monopolistic price adjustment and aggregate output. Review of Economic Studies, 49(4), pp. 517-531.

Schmitt-Grohe, S. and Uribe, M. (2003). Closing small open economy models. Journal of International Economics, 61, pp. 163-185.

Walsh, C. (2010). Monetary theory and policy. Cambridge, Massachusets: The MIT Press. 